\title{
CARACTERÍSTICAS FÍSICO-QUÍMICAS DE UM SÉRUM DESENVOLVIDO À BASE DO ÓLEO DE BURITI (MAURITIA FLEXUOSA) PARA PELE IDOSA
}

\author{
PHYSICO-CHEMICAL CHARACTERISTICS OF A SERUM DEVELOPED BASED ON \\ BURITI OIL (MAURITIA FLEXUOSA) FOR ELDERLY SKIN
}

\author{
Francisco Dimitre Rodrigo Pereira Santos ${ }^{1 *}$ Márcia Guelma Santos Belfort ${ }^{2} *$ Vanderlene Brasil $^{2}$ \\ Lucena $^{3 *}$ Joelma Alves Chaves ${ }^{4}$
}

\begin{abstract}
RESUMO
O envelhecimento é um processo natural, e irreversível, com o aumento da população idosa cresce a busca por cosméticos para retardar os sinais da idade e manter a pele saudável. O óleo de buriti (Mauritia flexuosa) é um fruto nativo do Brasil, rico em betacaroteno e ácidos graxos, que ajudam a regenerar e nutrir a pele. O objetivo deste estudo foi de apresentar as características físico-químicas de um sérum desenvolvido à base do óleo de buriti (Mauritia flexuosa) para pele idosa. Foi realizado um estudo descritivo de caráter experimental e cunho biotecnológico, onde inicialmente realizou-se a manipulação do sérum contendo óleo de buriti (Maurita flexuosa), após finalizada foram realizados os testes físico-químicos ( $\mathrm{pH}$, densidade, viscosidade e espalhabilidade) e testes de estabilidade preliminar da formulação. Os resultados dos testes foram positivos, foi observado uma densidade de $1.013 \mathrm{~g} / \mathrm{cm}^{3}$, com o pH 6.1, estando de acordo com o fisiológico que é de 4.6 e varia até 6.5. A determinação da viscosidade apresentou-se conforme padrão, o resultado da média de espalhabilidade foi de $2.6088 \mathrm{~cm}$. Conclui-se que o sérum apresenta propriedades físico-químicas favoráveis ao uso, apresentando-se estável em temperatura ambiente sendo esta ideal para a conservação das suas propriedades microscópicas, no entanto, em temperaturas a partir de $60^{\circ} \mathrm{C}$ o sérum apresentou alterações em sua cor original, podendo então ser feito análises microbiológicas posteriores para saber se foi afetado o tempo de conservação do produto.
\end{abstract}

Palavras-chave: Características Físico-Química. Sérum. Óleo de Buriti (Mauritia flexuosa). Pele Idosa.

\begin{abstract}
Aging is a natural and irreversible process, with the increase in the elderly population, the search for cosmetics grows to delay the signs of age and keep the skin healthy. Buriti oil (Mauritia flexuosa) is a fruit native to Brazil, rich in beta-carotene and fatty acids, which help to regenerate and nourish the skin. The aim of this study was to present the physical and chemical characteristics of a serum developed based on buriti oil (Mauritia flexuosa) for elderly skin. A descriptive study of an experimental nature and biotechnological nature was carried out, where initially the manipulation of the serum containing buriti oil (Maurita flexuosa) was carried out, after completing the physical-chemical tests $(\mathrm{pH}$, density, viscosity and spreadability) and tests preliminary stability of the formulation. The results of the tests were positive, a density of $1,013 \mathrm{~g} / \mathrm{cm} 3$ was observed, with $\mathrm{pH} 6.1$, being in accordance with the physiological which is 4.6 and varies up to 6.5 . The viscosity determination was presented as standard, the result of the average spreadability was $2.6088 \mathrm{~cm}$. It is concluded that the serum has physicochemical properties favorable to its use, being stable at room temperature and ideal for the conservation of its microscopic properties, however, at temperatures above $60^{\circ}$ $\mathrm{C}$ the serum showed changes in its color then subsequent microbiological analyzes can be carried out to see if the product's shelf life has been affected.
\end{abstract}

Keywords: Characteristics Physicochemical. Sérum. Buriti Oil (Mauritia flexuosa). Elderly Skin.

\footnotetext{
${ }^{1}$ Graduação em Fisioterapia. Especialização em Fisioterapia Gerontológica e Geriátrica. Mestrado em Ciências da Saúde. Doutorando em Engenharia Biomédica. Docente da Unidade de Ensino Superior do Sul do Maranhão-IESMA/UNISULMA. Docente da Universidade Estadual do Tocantins-UNITINS.

${ }^{2}$ Graduação em Farmácia Bioquímica. Especialização em Análises Clínicas com ênfase em Microbiologia. Mestrado em Patologia das Doenças Tropicais. Docente da Unidade de Ensino Superior do Sul do Maranhão-IESMA/UNISULMA. Docente da Universidade Estadual do Tocantins-UNITINS.

${ }^{3}$ Graduação em Ciências Biológicas. Especialização em Gerenciamento e Monitoramento Ambiental. Mestranda em Criminologia e Ciências Forenses. Coordenadora dos Laboratórios da Saúde da Unidade de Ensino Superior do Sul do MaranhãoIESMA/UNISULMA.

${ }^{4}$ Graduação em Estética e Cosmética. Cursando Especialização em Dermoestética Avançada e Cosmetologia.
}

https://doi.org/10.31011/reaid-2021-v.95-n.33-art.912 Rev Enferm Atual In Derme v. 95, n. 33, 2021 e-021002 


\section{INTRODUÇÃO}

Concomitante ao processo de senescência, o envelhecimento cutâneo é um processo natural, que está associado a alterações fisiológicas gradativas adquiridas ao longo dos anos, é causado por uma combinação de fatores intrínsecos e extrínsecos ${ }^{(1)}$. O intrínseco se inicia a partir dos 30 anos de idade e se agrava após os 45 anos, nas mulheres é mais evidente na menopausa em decorrência das alterações hormonais do estrogênio, testosterona e hormônio do crescimento; já o extrínseco está relacionado com os fototipos mais baixos na classificação de Fitzpatrick. Assim, pessoas de pele mais claras são mais suscetíveis ao dano solar, principalmente nas áreas mais expostas, podendo apresentar envelhecimento $\operatorname{precoce}^{(2)}$.

Independentemente da forma o envelhecimento cutâneo é um processo fisiológico, progressivo e inevitável, que ocorre naturalmente com o ser humano, está relacionado com a perda da capacidade funcional e de reservas do organismo, mudança da resposta celular aos estímulos, perda da capacidade de reparação e predisposição do organismo à doença ${ }^{(3)}$.

Com o aumento da expectativa de vida, cresce a busca para prevenir e retardar os sinais da idade, o que estimulam as pessoas a consumirem uma quantidade e variedade

https://doi.org/10.31011/reaid-2021-v.95-n.33-art.912 maior de produtos cosméticos, visando manter a pele jovial e saudável ${ }^{(4)}$.

Seguindo a tendência de cosméticos naturais e biocosméticos são produtos formulados com ingredientes naturais tem incorporado diferentes valores e conceitos, atribuídos a uma sociedade que cada vez mais valoriza o estilo de vida saudável, a aparência, bem estar e que se preocupam em preservar o meio ambiente ${ }^{(5)}$, com isso direcionamos a atenção ao óleo de buriti (Mauritia flexuosa).

O óleo de buriti (Mauritia flexuosa) extraído da poupa do fruto desperta grande interesse da indústria cosmética e farmacêutica, devido as suas propriedades químicas e físicas. O óleo é rico em ácidos graxos insaturados com predominância dos ácidos oleicos e ácidos graxos saturados, ácido palmítico, linoleico, linolênico e esteárico. Possui alto teor de antioxidantes, sendo o betacaroteno em maior quantidade, responsável pela coloração avermelhada do óleo $^{(6)}$.

O betacaroteno é um dos mais poderosos antioxidantes, conhecido por sua grande capacidade de renovação celular, devido sua capacidade de absorver radiações de luz visível e raios ultravioletas, Assim, o óleo de buriti se torna muito eficiente para indústria cosmética por conter filtro solar natural, que atua diminuindo o ressecamento da pele. Além dos ácidos graxos o óleo de buriti (Mauritia flexuosa) contém Rev Enferm Atual In Derme v. 95, n. 33, 2021 e-021002 
carotenoides e tocoferol, o que sugere uma boa alternativa temática e cosmética. Dentre os benefícios existentes, apontados pelas indústrias de cosméticos o óleo vegetal de buriti tem a função de lubrificar e renegar a barreira hidrolipídica da pele sofrida por lesões diariamente ${ }^{(7)}$.

\section{MÉTODO}

Tratou-se de um estudo descritivo de característica experimental, executado no Laboratório de Cosmética e Bioquímica da Unidade de Ensino Superior do Sul do Maranhão-UNISULMA, no período de dezembro de 2019 e junho de 2020.

Inicialmente foi realizado a esterilização da bancada e dos materiais, para
Partindo do exposto, o objetivo deste estudo é de apresentar as características físico-químicas de um sérum desenvolvido à base do óleo de buriti (Mauritia flexuosa) para pele idosa.

não haver risco de contaminação, em sequência para a manipulação foram utilizados como materiais de consumo o óleo de buriti (Mauritia flexuosa), óleo essencial de tea tree (melaleuca) e base sérum (Tabela 1) e materiais permanentes a balança digital (CLINK), calculadora, cronômetro (HERWEG), béquer, bastão de vidro, proveta, pHmetro (OHUAS), e espátula.

\section{TABELA 1 - Componentes utilizados na formulação do sérum a base do óleo vegetal de Buriti (Mauritia flexuosa). Imperatriz, MA, Brasil, 2020.}

\begin{tabular}{llll}
\hline Componentes & & Fase & Função \\
\hline \multicolumn{2}{c}{ Óleo vegetal de Buriti } & $\mathrm{O}$ & Emoliente \\
Óleo essencial de tea & tree & $\mathrm{O}$ & Conservante \\
$\begin{array}{l}\text { (melaleuca) } \\
\text { Base Sérum q.s.p }\end{array}$ & & & \\
\end{tabular}

Fonte: Dados da pesquisa, 2020.

Separou-se a fase aquosa (A) no béquer e depois a fase oleosa $(\mathrm{O})$ na proveta, em seguida verteu-se a fase oleosa $(\mathrm{O})$ na fase aquosa (A), mantendo sob agitação por alguns minutos, até a incorporação e então foram realizados os testes que qualidade, analisando as características organolépticas e físicoquímicas, tais como: aspecto, cor, odor, $\mathrm{pH}$, densidade, viscosidade e espalhabilidade após isso o fitocosmético foi devidamente envasada na embalagem adequada.

Os parâmetros organolépticos foram 
avaliados através dos órgãos dos sentidos para verificar se a formulação possui aspecto, cor e odor, dentro dos padrões exigidos, que foram realizados através da comparação com o produto de referência, possibilitando o reconhecimento primário do fitocosmético ${ }^{8}$.

A densidade foi verificada pela relação entre a massa e o volume de um corpo, medindo o grau de concentração de um determinado volume, ela é determinada com o picnômetro. É aplicado uma fórmula para encontrar os valores de M0, M1 e M2, onde:

toda a superfície, evitando a formação de bolhas. Pesou-se novamente, sendo determinado um peso total de $121 \mathrm{~g}$.

A medida do $\mathrm{pH}$ foi realizada através do método potenciômetro, utilizando o pHmetro digital (OHAUS) previamente calibrado, onde dois eletrodos foram imersos na amostra em estudo, utilizando eletrodos adequados para o tipo de formulação a ser analisada $^{(8)}$.

Para a determinação da viscosidade foi usado Viscosímetro Copo Zahn-2 Novotest TEC-7103, o teste procedeu-se pela realização do cálculo da formula: $\mathrm{V}=[(3.846 \times \mathrm{T})-17.3]$ $\mathrm{x} \mathrm{d}$, onde:

T é tempo de escoamento;

D é densidade da amostra.

Em seguida iniciou-se juntos o deposito da amostra no viscosímetro e foi realizado a contagem no cronômetro. Vale ressaltar que viscosidade é a resistência que o
$\mathrm{D}=$ densidade; massa do picnômetro vazio, em gramas;

M1 = massa do picnômetro com água purificada, em gramas;

M2 = massa do picnômetro com a amostra, em gramas.

Pesou-se o picnômetro vazio, que é correspondente a 49g. Em seguida, foi adicionado água purificada no picnômetro, pesou-se novamente, 73g. Foi colocado o sérum no picnômetro até a atingir produto oferece à deformação ou ao fluxo o teste de viscosidade consiste em medir a resistência de um material ao fluxo por meio da fricção ou do tempo de escoamento.

Realizou-se o teste de espalhabilidade $\operatorname{adaptado}^{(9)}$, onde pesou-se $0,3 \mathrm{~g}$ da amostra, colocou-se entre duas placas molde circular de acrílico com $17 \times 17 \mathrm{~cm}$ de diâmetro, com um orifício central de $1,2 \mathrm{~cm}$ de diâmetro e $0,5 \mathrm{~cm}$ de espessura, sendo uma delas dispostas sobre um papel milímetrado colocado na bancada. A cada 3 minutos adicionou-se pesos de $250 \mathrm{~g}, 500 \mathrm{~g}, 750 \mathrm{~g}$ e $1000 \mathrm{~g}$ sobre a placa superior, os diâmetros que se formaram nas posições horizontal e vertical foram medidos, realizou-se o cálculo da espalhabilidade a partir da equação descrita abaixo $^{(10)}$.

$$
\mathrm{Ei}=\mathrm{d}^{2} \cdot \pi / 4
$$


Onde: $\mathrm{Ei}=$ espalhabilidade da amostra para um determinado peso i em $\left(\mathrm{mm}^{2}\right)$ e $\mathrm{d}^{2}=$ diâmetro médio $(\mathrm{mm})$.

A amostra foi submetida a avaliação preliminar da estabilidade, 5 dias após a manipulação, empregou-se os testes de centrifugação, estresse térmico e ciclos de gelo e desgelo, com a finalidade de acelerar

Centrifuga (CELM) na velocidade de 300rpm durante 30 minutos, em seguida realizou-se a análise visual para a verificação de alterações na estabilidade do sérum.

No estresse térmico a amostra foi submetida a condições estremas de temperatura, visando antecipar possíveis alterações na formulação, pesou-se $5 \mathrm{~g}$ da amostra na balança digital (CLINK), onde foi submetida ao aquecimento em banho-maria nas seguintes faixas $40^{\circ} \mathrm{C}, 50^{\circ} \mathrm{C}, 60^{\circ} \mathrm{C}$ e $70^{\circ} \mathrm{C}$, mantendo-se por 30 minutos em cada possíveis reações que venham causar instabilidade no sérum ${ }^{(9)}$.

Sabendo que a centrifugação produz estresse na amostra, simulando um aumento na força de gravidade, aumentando a mobilidade das partículas, pesou-se 5 gramas da amostra e transferiu-se para tubos de ensaio em triplicata, as amostras foram submetidas ao teste de centrifugação em temperatura, a cada mudança e temperatura observou-se o aspecto, cor, odor e $\mathrm{pH}$ do sérum $^{(11)}$.

\section{RESULTADOS E DISCUSSÃO}

A formulação fitocosmética do sérum de óleo de buriti (Mauritia flexuosa) foi submetida inicialmente aos testes de controle de qualidade, descritos na sequência de observação das características organolépticas, estando de acordo com o esperado (Tabela 2).

TABELA 2 - Avaliação dos testes organolépticos da formulação do sérum à base de óleo de buriti (Mauritia flexuosa). Imperatriz, MA, Brasil, 2020.

\begin{tabular}{ccc}
\hline Análises & Resultado & Referência \\
\hline Aspecto & Creme Brilhante & 8 \\
Cor & Amarelo & 12 \\
Odor & Característico do óleo essencial de Tea tree (melaleuca) & 8 \\
\hline
\end{tabular}

Fonte: Dados da pesquisa, 2020.

Após a análise do sérum quanto as suas propriedades organolépticas representadas na tabela $2, \quad 0 \quad$ sérum apresentou-se na coloração amarela, com 
aspecto cremoso brilhante, textura macia, e odor característico do óleo essencial de Tea tree (melaleuca), pode-se classificar o odor com característica forte e sensação aromática, comparou-se o odor similar ao do mentol, mantendo-se estável macroscopicamente durante o estudo.

O processo de incorporação dos componentes, foi realizado com movimentos circulares, onde observou-se que o óleo

FIGURA 1 - Formulação do sérum à base do óleo de buriti (Mauritia flexuosa). Imperatriz, MA, Brasil, 2020.

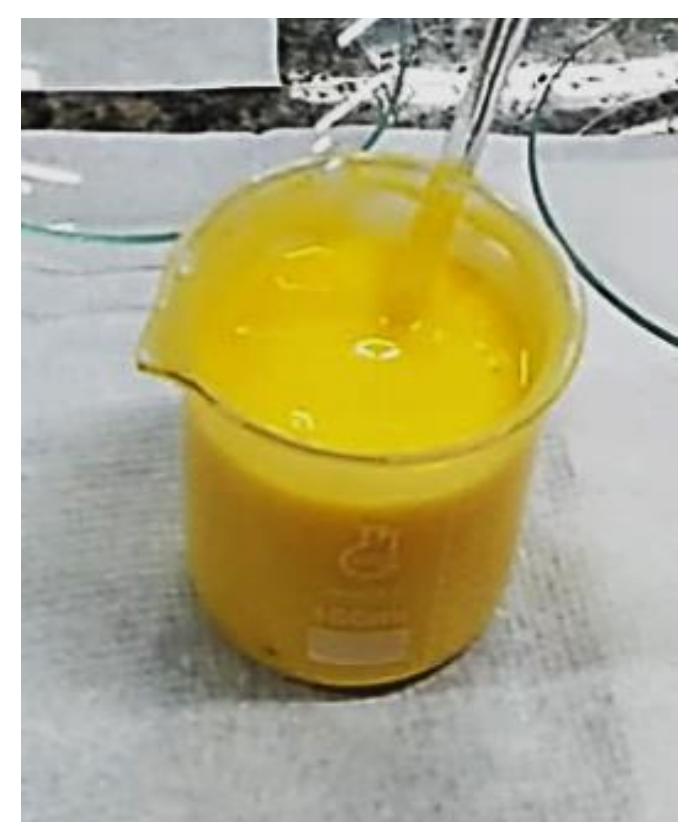

Fonte: Dados da pesquisa, 2020.

O sérum apresentou as mesmas características organolépticas (cremoso brilhante, textura macia, e odor característico do óleo essencial de Tea tree) assim que manipulado, ressaltando que tanto na versão creme quanto sérum o óleo de buriti (Mauritia flexuosa) é estável na formulação. Em pesquisa semelhante na formulação em creme https://doi.org/10.31011/reaid-2021-v.95-n.33-art.912 vegetal de buriti (Mauritia flexuosa), obteve uma boa incorporação na base sérum, com ausência de alterações no aspecto, cor e odor (Figura 1). A não ocorrência de separação de fases, indica que os componentes foram adicionados em concentrações adequadas, assim permitindo a estabilidade da formulação. 
importante para detectar se houve ou não incorporação de ar no produto, em decorrência disso pode haver diminuição da quantidade do produto e alterações no prazo de validade que será mais curto, o resultado foi satisfatório.

TABELA 3 - Resultados das análises físico-químicas da formulação do sérum a base do óleo de buriti (Mauritia flexuosa). Imperatriz, MA, Brasil, 2020.

\begin{tabular}{ccc}
\hline Análises Físico-químicas & Resultado & Referência \\
\hline Densidade & $1.013 \mathrm{~g} / \mathrm{cm}^{3}$ & 8 \\
$\mathrm{pH}$ & 6,1 & 14 \\
Viscosidade & Conforme padrão & 8 \\
Espalhabilidade & $2.609 \mathrm{~cm}$ & 10 \\
\hline
\end{tabular}

Fonte: Dados da pesquisa, 2020.

Quanto a densidade teve valor de $0.9818 \mathrm{~g} / \mathrm{cm}^{3}$, não havendo incorporação de ar na amostra. Esta análise permite verificar a incorporação de ar no produto, sua instabilidade podendo alterar na cor e odor do cosmético, isso poderá interferir no prazo de validade do cosmético ${ }^{(12)}$, assim como identificado na amostra estudada.

$\mathrm{O}$ sérum apresentou um $\mathrm{pH}$ de 6.1 estando dentro dos padrões de segurança, resultado esperado para esse tipo de formulação, sendo este adequado ao $\mathrm{pH}$ da pele, que pode variar de acordo com cada região do corpo e idade, o $\mathrm{pH}$ fisiológico cutâneo varia entre 4.6 e 6.0 sendo levemente ácido contribuindo assim para a proteção fungicida e bactericida da superfície cutânea ${ }^{(13)}$.

Analisando os dados apresentados no gráfico 1 verificou-se que houve variações no pH durante o período de onze dias da análise com a amostra armazenada em temperatura ambiente, no segundo, terceiro e quarto dia foi observado que o $\mathrm{pH}$ manteve $\cong 6.1$, apresentando $\log$ o em seguida uma pequena queda e pico máximo de 6.2 no nono dia e ao final dos onze dias estando de 6.1. Foi possível perceber que ao longo dos onze dias a variação do valor máximo para o valor mínimo foi de 0.5 apresentando uma variação relativamente baixa estando a margem dentro dos padrões fisiológicos ${ }^{(14)}$. 
GRÁFICO 1 - Demonstração da variação pH do sérum à base do óleo de buriti (Mauritia flexuosa) durante onze dias. Imperatriz, MA, Brasil, 2020.

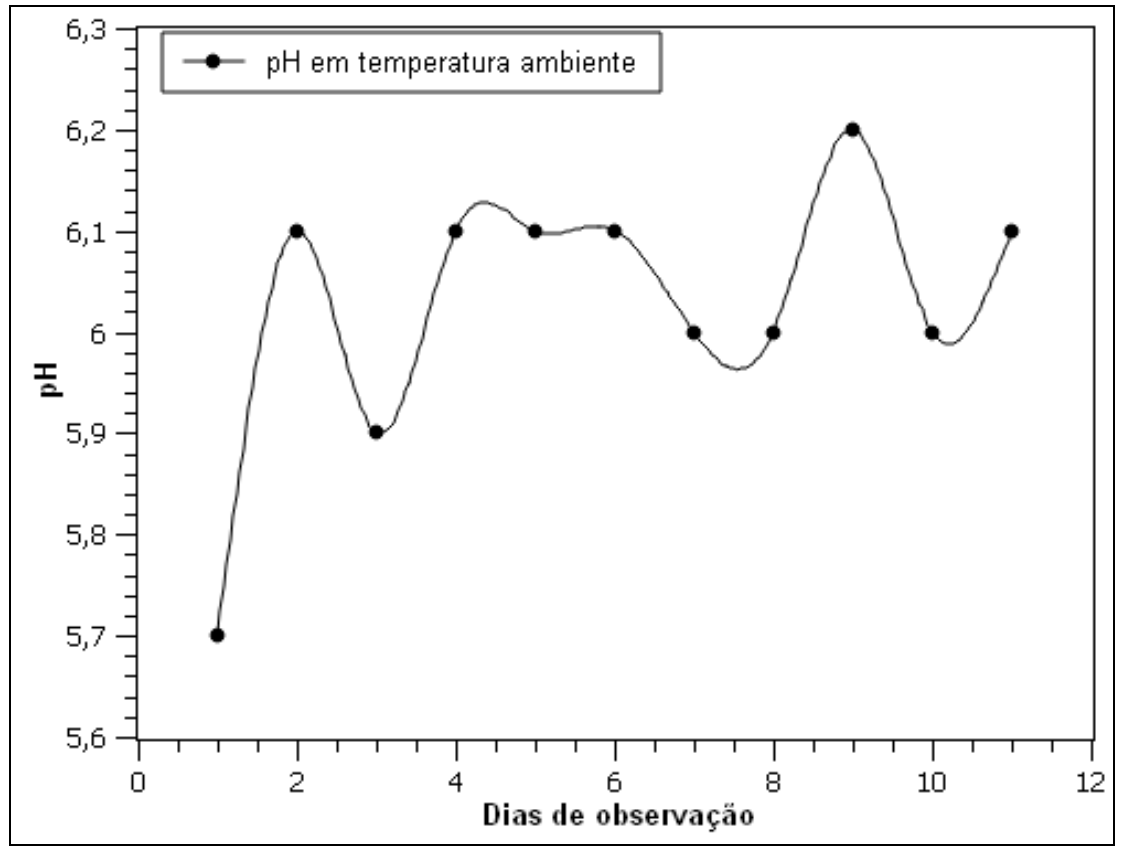

Fonte: Dados da pesquisa, 2020.

De acordo com a figura 2 a análise da viscosidade foi encontrada um valor de $1.940 \mathrm{mPa}$.s para viscosidade, com o tempo de 4 minutos, onde avaliou-se a consistência do produto, através da resistência ao escoamento que a formulação oferece. Através dos resultados encontrados, foi possível afirmar que a formulação cosmética se encontra dentro do padrão permitido.

FIGURA 2 - Teste de viscosidade do sérum à base óleo de buriti (Mauritia flexuosa). Imperatriz, MA, Brasil, 2020. 


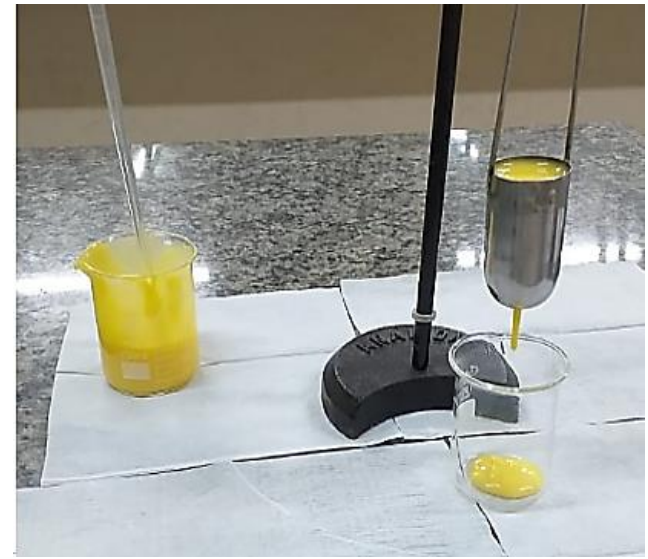

Fonte: Dados da pesquisa, 2020.

A análise da viscosidade deve ser definida pelo formulador em conformidade com a percepção visual e sensorial decorridas de alterações e deve-se levar em conta a possibilidade de aceitação do consumidor. O sérum em questão obteve características desejáveis, conforme pode-se observar na figura 02 .
A espalhabilidade do sérum aumentou a cada adição de peso no tempo de 3 minutos, onde $\mathrm{o}$ foi encontrado uma média de $2.6088 \mathrm{~cm}$ (Gráfico 2). Apresentando assim uma boa espalhabilidade sobre a pele, com capacidade de se espalhar e abranger o local da ação.

GRÁFICO 2 - Demonstração dos resultados da espalhabilidade da formulação do sérum à base do óleo de buriti (Mauritia flexuosa), mediante a adição de pesos graduais, Imperatriz, MA, Brasil, 2020.

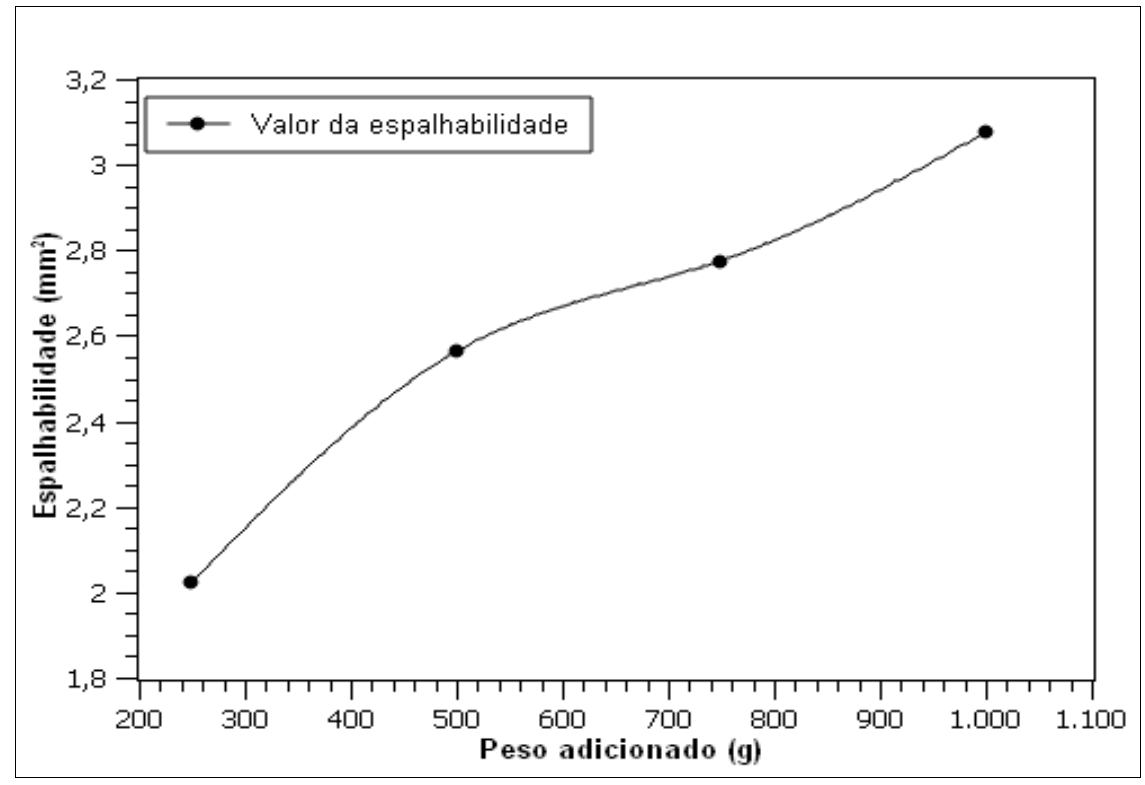

Fonte: Dados da pesquisa, 2020. 
Ao observar a correlação entre o peso e a espalhabilidade foi possível perceber que a medida que o peso aumenta a espalhabilidade aumenta proporcionalmente, apresentando assim uma correlação positiva entre as variáveis com achados estatisticamente significativos sendo encontrado no presente estudo um $\mathrm{p}=0.02$ (Tabela 5).

TABELA 5 - Correlação entre o peso e a espalhabilidade do sérum à base do óleo de buriti (Mauritia flexuosa). Imperatriz, MA, Brasil, 2020.

\begin{tabular}{lccccccc}
\hline \multicolumn{1}{c}{ Variáveis } & Média $( \pm \mathbf{d p})^{\mathbf{a}}$ & Mediana & Variância & $\begin{array}{c}\text { Valor } \\
\text { Máximo }\end{array}$ & $\begin{array}{c}\text { Valor } \\
\text { Mínimo }\end{array}$ & $\mathbf{r}^{\mathbf{b}}$ & $\mathbf{p}$ \\
\hline Espalhabilidade & $2.6088( \pm 0.4438)$ & 2.6688 & 0.197 & 3.075 & 2.0225 & 0.1 & 0.02 \\
Peso & $625( \pm 322.7486)$ & 625 & 104166.7 & 1000 & 250 & & \\
\hline
\end{tabular}

${ }^{\mathrm{a} D e s v i o ~ P a d r a ̃ o . ~}{ }^{\mathrm{b}}$ Relação de Pearson.

Fonte: Dados da pesquisa, 2020.

Para a realização do teste foi utilizado os seguintes materiais: paquímetro, placas molde circular de acrílico, pote de vidro, papel milímetrado, como demonstra a figura 03. De acordo com os resultados obtidos, descritos na tabela 05 a espalhabilidade do sérum aumentou a cada adição de peso, no tempo de 3 minutos, onde as amostras A e B apresentaram um leve aumento na espalhabilidade, já entre a amostra C com o peso de $750 \mathrm{~g}$ e amostra D com peso de $1000 \mathrm{~g}$ (Figura 4) apresentaram excelentes valores de espalhabilidade, com isso, a adição do óleo de buriti na base sérum, mostrou-se viável pois as características físico-químicas são consideradas aceitáveis.

FIGURA 3 - Materiais utilizados no teste de espalhabilidade. Imperatriz, MA, Brasil, 2020.

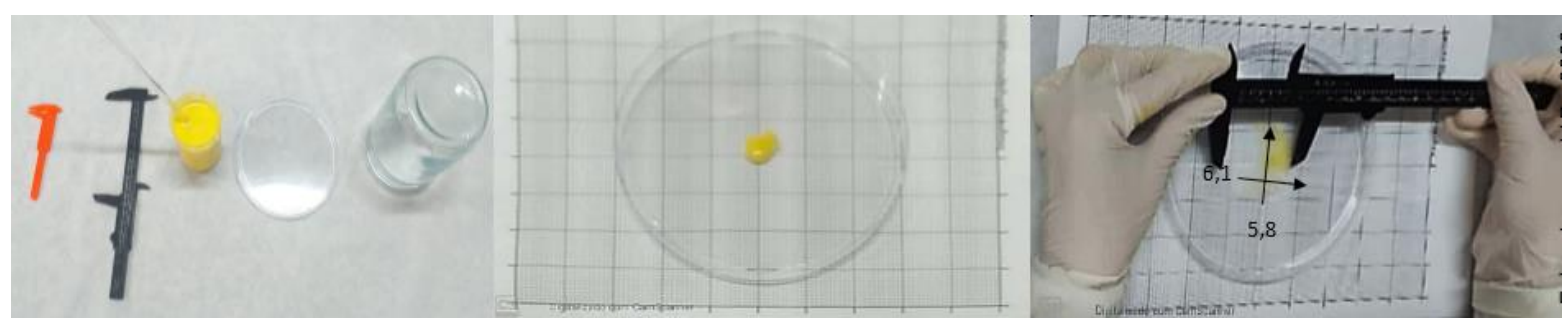

Fonte: Dados da pesquisa, 2020.

FIGURA 4 - Teste de espalhabilidade com adição de pesos. Imperatriz, MA, Brasil, 2020. 


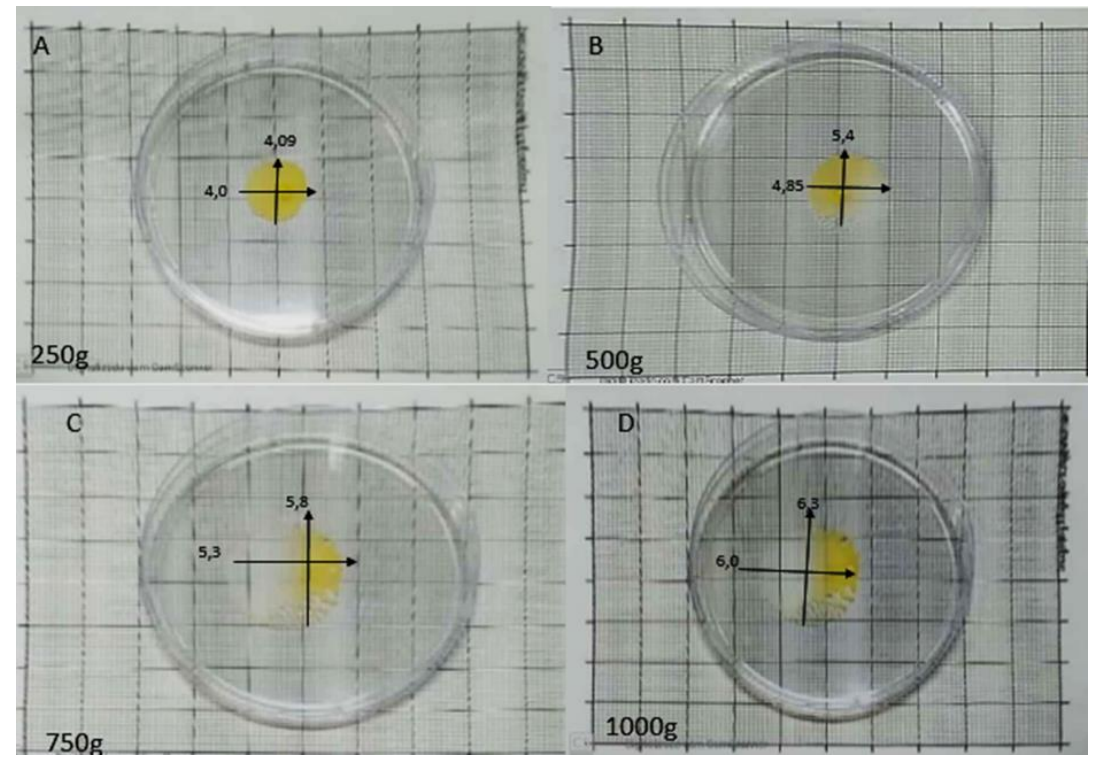

Fonte: Dados da pesquisa, 2020.

Em estudo anterior obteve-se valores que variam de $1500 \mathrm{~mm}^{2}$ até $4500 \mathrm{~mm}^{2}$ tanto para emulsões aniônicas como para nãoiônicas, se apresentado uma carga oleosa mais elevada por ser destinado a pele ressecada ${ }^{(15)}$.

O teste de espalhabilidade determina a capacidade que uma formulação apresenta em se empalhar, quando submetida a uma determinada força sobre o produto aplicado na pele e está relacionado com viscosidade, sendo uma das características essenciais das emulsões de aplicação tópica. Emulsões à base de óleo de buriti com adição de óleo essencial de Tea tree (melaleuca) apresenta uma boa cobertura de área com pouca quantidade de produto, tendo assim uma boa espalhabilidade ${ }^{(16)}$.

O teste de centrifugação proporciona informações antecipadas de estabilidade da formulação tais como separação de fases, floculação e coalescência, não houve alterações na estabilidade do sérum, apresentando-se estável e sem a necessidade de refazer a formulação, como é possível observar na (Tabela 6), isto indica que o sérum possui estabilidade física adequada.

TABELA 6 - Resultados das características organolépticas do teste de centrifugação do sérum à base do óleo de buriti (Mauritia flexuosa), após 5 dias de preparo da formulação. Imperatriz, MA, Brasil, 2020.

\begin{tabular}{ccc}
\hline Análise & Tempo (em dias) & Resultado \\
\hline Aspecto & 5 & Cremoso brilhante \\
Cor & 5 & Amarelo \\
Odor & 5 & Característico do óleo essencial de Tea tree (melaleuca) \\
Centrifugação & 5 & Estável \\
\hline
\end{tabular}

Fonte: Dados da pesquisa, 2020.

https://doi.org/10.31011/reaid-2021-v.95-n.33-art.912 Rev Enferm Atual In Derme v. 95, n. 33, 2021 e-021002 
Os resultados positivos sobre o creme contendo óleo de buriti, no teste de centrifugação as amostras se mantiveram estáveis durante todo o estudo de estabilidade, não sendo observado separações de fases e nem a formação de exsudato ${ }^{(17)}$.

A amostra foi submetida a condições de estresse térmico, por um período de 2 horas, a cada aumento de temperatura, realizou-se análises para verificar possíveis surgimentos de alterações na estabilidade do sérum, os resultados encontrados estão demostrados na (Tabela 7).

TABELA 7 - Análise das características organolépticas e do pH do sérum à base do óleo de buriti (Mauritia flexuosa), após o teste de estresse térmico. Imperatriz, MA, Brasil, 2020.

\begin{tabular}{clccc}
\hline Temperatura & \multicolumn{1}{c}{ Aspecto } & Cor & Odor & pH \\
\hline $40^{\circ} \mathrm{C}$ & Cremoso & Amarelo & Essência de Tea tree (melaleuca) & 6,1 \\
$50^{\circ} \mathrm{C}$ & Cremoso & Amarelo & Essência de Tea tree (melaleuca) & 5,9 \\
$60^{\circ} \mathrm{C}$ & Levemente aquoso & Amarelo & Essência de Tea tree (melaleuca) & 6.3 \\
\hline
\end{tabular}

Fonte: Dados da pesquisa, 2020.

A partir dos resultados obtidos, observou-se que até $50{ }^{\circ} \mathrm{C}$ não houve alterações significativas no sérum, porém na temperatura de $60^{\circ} \mathrm{C}$, houve modificações no aspecto e $\mathrm{pH}$, onde a amostra se apresentou levemente aquosa e aumentou o pH. Essa modificação ocorre quando amostras são submetidas a temperaturas extremas pode ocorrer desidratação e decomposição, modificando a cor e o valor do $\mathrm{pH}$, podendo apresentar pequenas variações ${ }^{(18)}$.

\section{CONCLUSÃO}

A partir do seguinte estudo verificouse que é possível a utilização do óleo de buriti https://doi.org/10.31011/reaid-2021-v.95-n.33-art.912
(Mauritia flexuosa), em formulações cosméticas para pele idosa em função dos benefícios encontrados nas literaturas e nos resultados obtidos, aonde esses foram aceitáveis estando dentro dos padrões exigidos pela legislação; sabendo que além de ser um fruto regional do cerrado o mesmo apresenta um potencial econômico devido as suas propriedades antioxidante, umectante, cicatrizante e atividade bactericida, além disso é um produto que tem ação fotoprotetora absorvendo os raios ultravioleta, favorecendo a hidratação da pele envelhecida.

Portanto, assim como aponta a literatura $^{(19)}$ a prevenção da lesão na pele idosa parte do cuidado ao longo do dia, Rev Enferm Atual In Derme v. 95, n. 33, 2021 e-021002 
mantendo a homeostase, nutrição e hidratação cutânea. Com base nas conclusões deste estudo sugere-se com alternativa para prevenção de lesão cutânea o uso do sérum a base de óleo de buriti (Mauritia flexuosa), no entanto estudos clínicos precisam ser elaborados.

\section{REFERENCIAS}

1. World Health Organization. Integrated Care for Older People: Guidelines on Community-Level Interventions to Manage Declines in Intrinsic Capacity [Internet]. 2017 [acesso em 15 de set 2020]; Geneva. Disponível em: https://www.ncbi.nlm.nih.gov/books/NBK488 $\underline{250 / .}$.

2. Jugé R, Rouaud-Tinguely $\mathrm{P}$, Breugnot $\mathrm{J}$, Servaes K, Grimaldi C, Roth MP, Coppin H, Closs B. Shift in skin microbiota of Western European women across aging. J Appl Microbiol [Internet]. 2018 [acesso em 17 de set 2020]; 125(3):907-916. Disponível em: https://doi.org/10.1111/jam.13929.

3. Katoh N, Tennstedt D, Abellan van Kan G, Saint Aroman M, Loir A, Bacqueville D, Duprat L, Guiraud B, Bessou-Touya S, Duplan H. Gerontodermatology: the fragility of the epidermis in older adults. J Eur Acad Dermatol Venereol [Internet]. 2018 [acesso em 30 de set 2020]; 32 Suppl 4:1-20.
Disponível

em:

https://doi.org/10.1111/jdv.15253.

4. Abels C, Angelova-Fischer I. Skin Care Products: Age-Appropriate Cosmetics. Curr Probl Dermatol [Internet]. 2018 [acesso em 30 de set 2020]; 54:173-182. Disponível em: https://doi.org/10.1159/000489531.

5. Kostyuk V, Potapovich A, Albuhaydar AR, Mayer W, De Luca C, Korkina L. Natural Substances for Prevention of Skin Photoaging: Screening Systems in the Development of Sunscreen and Rejuvenation Cosmetics. Rejuvenation Res [Internet]. 2018 [acesso em 29 de set 2020]; 21(2):91-101. https://doi.org/10.1089/rej.2017.1931.

6. Berni P, Pinheiro AC, Bourbon AI, Guimarães M, Canniatti-Brazaca SG, Vicente AA. Characterization of the behavior of carotenoids from pitanga (Eugenia uniflora) and buriti (Mauritia flexuosa) during microemulsion production and in a dynamic gastrointestinal system. J Food Sci Technol [Internet]. 2020 [acesso em 01 out 2020]; 57(2):650-662.

https://doi.org/10.1007/s13197-019-04097-7.

7. Ferreira MOG, Lima IS, Ribeiro AB, Lobo AO, Rizzo MS, Osajima JA, Estevinho LM, Silva-Filho EC. Biocompatible Gels of Chitosan-Buriti Oil for Potential Wound 
Healing Applications. Materials (Basel) [Internet]. 2020 [acesso em 01 out 2020]; 13(8):1977.

https://doi.org/10.3390/ma13081977.

8. Brasil. Ministério da Saúde. Agência Nacional de Vigilância Sanitária. Guia de controle de qualidade de produtos cosméticos. Brasília, DF, 2007.

9. Brasil. Ministério da Saúde. Agência Nacional de Vigilância Sanitária. Guia de estabilidade de produtos cosméticos. 1. Ed. Brasília, DF, 2004.

10. Borghetti SGS, Knorst MT.

Desenvolvimento e avaliação da estabilidade física de loções O/A contendo filtros. Rev Bras Ciênc Farm [Internet]; 2006 [acesso em 02 out 2020]; 42(4): 531-537. Disponível em: https://www.scielo.br/pdf/rbcf/v42n4/a08v42 n4.pdf.

11. Lima, CG, et al. Desenvolvimento e avaliação da estabilidade física de emulsões O/A contendo óleo de babaçu (Orbignya olrifera). Rev Bras Farm [Internet]; 2008 [acesso em 05 out 2020]; 89(3): 239-245. Disponível em: https://rbfarma.org.br/files/146_239a245_des envolvimento_emulsoes.pdf.
12. Saraiva, LCF, Rondenelly BS. Desenvolvimento de um creme à base de óleo de buriti (Mauritia flexuosa). Rev FAESF [Internet]; 2017 [acesso em 05 out 2020]; 1(1): 1-12. Disponível em: http://faesfpi.com.br/revista/index.php/faesf/a rticle/view/24.

13. Silva FVF, et al. Desenvolvimento e controle de qualidade de um gel-creme antiacneico a base do óleo da Copaífera officinalis L. (copaíba). Rev Eletr Acervo Saúde [Internet]; 2019 [acesso em 05 out 2020]; 30(30): 1-10. Disponível em: https://doi.org/10.25248/reas.e974.2019.

14. Freitas EV, Py L. Tratado De Geriatria e Gerontologia. 4 $4^{\mathrm{a}}$.ed. São Paulo: Guanabara Koogan, 2016.

15. Spellmeier F. Estudo comparativo entre dois métodos de produção de bases emulsionadas através da estabilidade acelerada. [monografia]. Lajeado: Universidade do Vale do Taquari; 2005.

16. Romero ER. Pesquisa e desenvolvimento de emulsões à base de óleos vegetais (buriti, cenoura e urucum) e bases auto emulsionantes aditivadas de óleo de melaleuca e ácido salicílico para o tratamento de pele acneica. [dissertação]. Ribeirão Preto: Universidade de São Paulo, Faculdade de Ciências 
Farmacêuticas de Ribeirão Preto; 2017 [acesso em 07 out 2020]. Disponível em: https://doi.org/10.11606/D.60.2017.tde30062017-153914.

17. Oliveira JC, Maia LO, Souza ECO, Tescarollo IL. Avaliação sensorial e físicoquímica de hidratante formulado com óleo de buriti. Visão Acadêmica [Internet]; 2016 [acesso em 07 out 2020]; 17(1): 31-44. Disponível em: https://revistas.ufpr.br/academica/article/view/ $\underline{46470 / 28850 .}$.

18. Borges CMD. Desenvolvimento e estabilidade acelerada de emulsão contendo óleo de Mauritia flexuosa L. [monografia]. Brasília: Universidade de Brasília; 2019.

19. Gomes BE, Souza PV de, Silva GD da, Rocha RM, Kuriyama SN, Silvino ZR. Sistematizando o conhecimento acerca da prevenção das lesões do tipo skin tears na pele senil. Rev Enf Atual In Derme [Internet]. 2019 [acesso em 02 nov 2020]; 77(15). Disponível em: https://doi.org/10.31011/reaid-2016-v.77n.15-art.377.

Submissão: 2020-10-14

Aprovado: 2020-12-23 